\title{
ATO REGULAMENTAR NĀO ESTÁ SUJEITO A CONTROLE DE CONSTITUCIONALIDADE
}

Ag. Reg. na Ação Direta de Inconstitucionalidade 2.792-1

Minas Gerais

\author{
Relator: Min. Carlos Velloso \\ Agravante(s): Partido Trabalhista Brasileiro - PTB \\ Advogado(a/s): Mauro Borges Loch e outro(a/s) \\ Agravado(a/s): Tribunal de Justiça do Estado de Minas Gerais
}

EMENTA: CONSTITUCIONAL. ADMINISTRATIVO. REGULAMENTO. NOTÁRIOS. CONTROLE CONCENTRADO DE CONSTITUCIONALIDADE: IMPOSSIBILIDADE. Resolução n' $350 / 99$ e Editais 001/99 e 002/99 do Tribunal de Justiça do Estado de Minas Gerais.

I. - Ato regulamentar não está sujeito ao controle de constitucionalidade, dado que se vai ele além do conteúdo da lei, pratica ilegalidade e não inconstitucionalidade. Somente na hipótese de não existir lei que preceda o ato regulamentar, é que poderia este ser acoimado de inconstitucional, assim sujeito ao controle de constitucionalidade. Precedentes do Supremo Tribunal Federal.

II. - No caso, têm-se atos regulamentares da Lei 12.919/98, do Estado de Minas Gerais.

III. - Agravo regimental não provido.

\section{ACÓRDÃO}

Vistos, relatados e discutidos estes autos. acordam os Ministros do Supremo Tribunal Federal. em Sessão Plenária. na conformidade da ata de julgamentos e das notas taquigráficas, por unanimidade. em negar provimento ao agravo regimental, nos termos do voto do Relator. Votou o Presidente. Ausentes, justificadamente, neste julgamento, os Senhores Ministros Maurício Corrêa. Presidente, Marco Aurélio e Carlos Britto. Presidiu o julga- mento o Senhor Ministro Nelson Jobim, VicePresidente.

Brasília, 19 de fevereiro de 2004.

Nelson Jobim - Presidente

Carlos Velloso - Relator

\section{RELATÓRIO}

O Sr. Ministro CARLOS VELLOSO: Trata-se de agravo regimental, fundado no art. 317 do R.I./S.T.F., interposto pelo PAR- 
TIDO TRABALHISTA BRASILEIRO - PTB, da decisão (fls. 179/188) que não conheceu da presente ação direta de inconstitucionalidade, ao entendimento de que "os atos normativos impugnados são secundários, porque atos de regulamentação de norma primária, especialmente da Lei Estadual 12.919/98" (fl. 185).

Diz o agravante que o presente caso não se amoldaria aos precedentes citados na decisão ora agravada.

Sustenta, mais, em síntese, o seguinte:

a) existência de precedentes favoráveis ao agravante em casos semelhantes (ADI 1.352MC/DF, Ministro Moreira Alves, "D.J." de 18.5.2001; 2.151-MC/MG, Ministro Marco Aurélio, “D.J.” de 22.11.2002).

b) inexistência, no presente caso, de "interpretação administrativa que tenha projetado posição ultra legem, citra legem ou contra legem, mas, pelo inverso, os atos legislativos atacados estão em perfeita sintonia com a lei a partir da qual foram editados" (fl. 195). Entretanto, "tanto a lei, como os atos de hierarquia inferior, encerram inconstitucionalidades" (fl. 196);

c) ocorrência de invasão da competência do Poder Legislativo, mormente porque a Resolução $350 / 99$ do Eg. Tribunal de Justiça do Estado de Minas Gerais "efetivamente regulamentou a atividade notarial, estipulando regras para o concurso público de ingresso e remoção, matéria reservada à lei em sentido formal" (fl. 196), resolução essa que estaria em absoluta consonância com a lei;

d) ter sido o art. $8^{\circ}, \S 2^{\circ}$, da Lei Estadual 12.919/98 objeto de ação direta de inconstitucionalidade (ADI 2.151-MC/MG, Ministro Marco Aurélio, "D.J." de 22.11.2002);

e) ocorrência de ofensa do art. $2^{\circ}, \S 5^{\circ}, d a$ Resolução 350/99 do Eg. Tribunal de Justiça do Estado de Minas Gerais ao art. 236, $\$ 3^{\circ}$, da Constituição Federal, na medida em que a exclusão, promovida pelo dispositivo ora atacado, das serventias providas por delegação efetiva violaria frontalmente a necessidade de concurso público de provas e títulos, inexistindo, nesse ponto, "crise de legalidade, mas a própria inconstitucionalidade, não havendo que se falar em violação reflexa" (fl. 199).
Requer, ao final, o agravante a reconsideração da decisão ora impugnada ou, caso assim não se entenda, o julgamento do presente agravo pelo Plenário desta Corte, "para declarar inconstitucional a Resolução 350/99, do Tribunal de Justiça de Minas Gerais, e os editais 001/99 e 002/99, do Tribunal de Justiça de Minas Gerais, e, sucessivamente, dos dispositivos do item 6.1 do edital $01 / 99$ e de parte do artigo $8^{\circ}$, $\S 2^{\circ}$, da Resolução $350 / 99^{\prime \prime}$ (fl. 199).

É o relatório.

\section{VOTO}

O Sr. Ministro CARLOS VELLOSO (Relator): Assim a decisão agravada, ora sob exame:

" (...)

Destaco do parecer do eminente Procurador-Geral da República, Prof. Geraldo Brindeiro:

"(...)

7. Preliminarmente, verifica-se não comportar conhecimento a presente ação direta de inconstitucionalidade, dada a ausência de confronto direto entre os atos normativos impugnados e a Constituição Federal.

8. Note-se que o art. $1^{\circ}$ da Resolução atacada estabelece que 'os concursos públicos para habilitação ao exercício das atividades notariais e de registro, bem como para a remoção de titulares, no âmbito do Estado de Minas Gerais, serão realizados nos termos da Lei Federal $n^{\circ}$ 8.935/94 e da Lei Estadual $n^{\circ}$ 12.919/98'. A primeira lei regulamenta o art. 236 da Constituição Federal, dispondo sobre os serviços notariais e de registro, e a segunda sobre os concursos de ingresso e remoção nos serviços notariais e de registro no Estado de Minas Gerais.

9. Ocorre que tanto os Editais como a Resolução, na parte em que atacados, praticamente reiteram disposições contidas nas leis mencionadas, sem que as mesmas tenham sido impugnadas pelo requerente.

10. Vê-se, assim, que o exame da apontada inconstitucionalidade da Resolução $n^{\circ} 350$, 
bem como dos Editais, que com ela se relacionam, demanda seu prévio cotejo com normas infraconstitucionais, revelando-se o eventual conflito no campo da legalidade, inadmissível em sede de controle concentrado de constitucionalidade, conforme ampla e pacífica jurisprudência dessa egrégia Corte, bem ilustrada no despacho proferido pelo eminente Ministro CELSO DE MELLO, ao negar conhecimento à ADI (MC) no 2207/AL, do qual oportuno extrair o seguinte excerto:

' $\mathrm{Na}$ realidade, como os atos infralegais ora questionados foram editados em função da Lei estadual $n^{\circ} 5.986 / 97$, torna-se claro que a situação de antinomia acaso existente poderia traduzir, eventualmente, comportamento administrativo efetivado em desarmonia com o texto da lei, circunstância essa que se revelaria apta a configurar hipótese de simples incompatibilidade legal. A controvérsia ora em análise conduz a uma só conclusão: quer se trate de normas editadas contra legem, quer se cuide de regras promulgadas citra legem, a situação de contraste a ser examinada reduzse, no caso, a uma única hipótese, consistente no reconhecimento de que atos de menor hierarquia jurídica teriam transgredido a normatividade emergente de um estatuto de caráter meramente legal. Vê-se, portanto, que o eventual extravasamento dos limites materiais do diploma legislativo em causa (Lei estadual $n^{\circ}$ 5.986/97), por parte dos atos ora questionados, poderá configurar estado de direta insubordinação aos comandos da lei, matéria essa que, em função de sua natureza mesma, achase pré-excluída do âmbito temático de incidência da fiscalização abstrata de constitucionaiidade. De outro lado, e mesmo que, a partir do vício jurídico da ilegalidade, fosse lícito vislumbrar, num desdobramento ulterior, a potencial violação da Carta Magna, ainda assim estar-se-ia em face de situação de inconstitucionalidade indireta ou oblíqua, cuja apreciação não se revela possível em sede jurisdicional concentrada: "Não cabe ação direta quando o ato normativo questionado, hierarquicamente inferior à lei, deve ser confrontado diretamente com a legislação ordinária e só indiretamente com a Constituição, pois, neste caso, cuida-se de ilegalidade e não de inconstitucionalidade.' (ADI 1.883-CE, Rel. Min. MAURÍCIO CORRÊA - grifei) A jurisprudência do Supremo Tribunal Federal, ao refletir esse entendimento, firmou-se no sentido de repelir a possibilidade de controle juridicional de constitucionalidade, por via de ação, nas situações em que a impugnação in abstracto venha a incidir sobre atos que, não obstante veiculadores de conteúdo normativo, ostentem caráter meramente ancilar ou secundário, precisamente porque editados em função das leis a que aderem e cujo texto pretendem regulamentar ou implementar: 'As resoluções editadas pelo Poder Público, que veiculam regras de conteúdo meramente regulamentar, não se submetem à jurisdição constitucional de controle in abstracto, pois tais atos estatais têm por finalidade, em última análise, viabilizar, de modo direto e imediato, a própria execução da lei... Se a interpretação administrativa da lei divergir do sentido e do conteúdo da norma legal que o Decreto impugnado pretendeu regulamentar, quer porque se tenha projetado ultra legem, quer porque tenha permanecido citra legem, quer porque tenha investido contra legem, a questão posta em análise caracterizará típica crise de legalidade, e não de inconstitucionalidade, a inviabilizar a utilização do mecanismo processual de fiscalização normativa abstrata.' (ADI 561-DF, Rel. Min. CELSO DE MELLO). É por tal razão que esta Suprema Corte já advertiu que crises de legalidade - que irrompem no âmbito do sistema de direito positivo, caracterizadas pela inobservância, por parte da autoridade pública, do seu dever jurídico de subordinação normativa à lei revelam-se, por sua natureza mesma, insuscetíveis de controle jurisdicional concentrado (RTJ 152/352, Rel. Min. CELSO DE MELLO), pois a finalidade a que se acha vinculado o processo de fiscalização normativa abstrata restringe-se, tão-somente, à aferição de situações configuradoras de inconstitucionalidade direta, imediata e frontal (RTJ 133/69, Rel. Min. CARLOS VELLOSO - RTJ 134/558, Rel. Min. CELSO DE MELLO - RTJ 139/67, Rel. Min. CELSO DE MELLO RTJ 137/580, Rel. Min. CARLOS VELLO$\mathrm{SO})$.' 
11. É certo que o $\S 2^{\circ}$ do art. $8^{\circ}$ da Resolução $n^{\circ} 350 / 99$, bem como os Editais $n^{\circ} 001 / 99$ e $\mathrm{n}^{\circ} 002 / 92$, ora questionados, são objeto da Adi $\mathrm{n}^{\circ}$ 2151-6/MG, a qual foi admitida integralmente, entretanto, naquele julgado também fora atacado o $\S 2^{\circ}$ do art. $8^{\circ}$ da Lei $n^{\circ}$ 12.919/98 do Estado de Minas Gerais.

12. Aquela ação direta foi conhecida em sua totalidade, por maioria, vencido o eminente relator à época, Ministro MARCO AURÉLIO, na sessão plenária realizada em 10/5/00, e também, por maioria, vencido o relator, foi deferido o pedido de medida liminar, para suspender, até a decisão final da ação, tão-somente a eficácia do $\S 2^{\circ}$, do art. $8^{\circ}$ da Lei $n^{\circ}$ 12.919/98, do Estado de Minas Gerais, em acórdão assim ementado:

"CONTROLE CONCENTRADO DE CONSTITUCIONALIDADE - ATOS ADMINISTRATIVOS. $\mathrm{Na}$ dicção da ilustrada maioria, entendimento em relação ao qual guardo reservas, ajuizada ação direta de inconstitucionalidade contra lei no sentido formal e material, bem como no tocante aos demais atos a ela vinculados, edital e resolução - cumpre admitir integralmente, contra todos os instrumentos citados, o controle concentrado.

CONCURSO PÚBLICO - NOTÁRIO CLIENTELA. Ainda de acordo com a douta maioria, conclusão em torno da qual também guardo reservas, surge a relevância do pedido de concessão de liminar, no que o diploma local, ante a Lei federal $\mathrm{n}^{\circ} 8.935 / 94$, revela a clientela do concurso para preenchimento do cargo de notário, em serviço notarial e de registro, como sendo a constituída por titulares, substitutos e escreventes juramentados legalmente nomeados - artigo $8^{\circ}, \S 2^{\circ}$, da Lei $n^{\circ} 12.919 / 98$, do Estado de Minas Gerais."

13. Assim estabelece o $\S 2^{\circ}$ do art. $8^{\circ}$ da Lei $\mathrm{n}^{\circ} 12.919 / 98$, do Estado de Minas Gerais, que foi suspenso na ação acima referida:

"Art. $8^{\circ}$.

$\$ 2^{\circ}$ Do concurso público poderá participar candidato não bacharel em Direito que tenha completado, até a data da primeira publicação do edital do concurso de provas e títulos, 10 (dez) anos de exercício em serviço notarial ou de registro como titular, substituto ou escrevente juramentado, legalmente nomeado."

14. Por sua vez, o $\$ 2^{\circ}$, do art. $8^{\circ}$, da Resolução $n^{\circ} 350 / 99$, do Tribunal de Justiça do Estado de Minas Gerais, que é aqui impugnado, reitera, essencialmente, o disposto na norma acima transcrita, como vê-se do seu teor, in verbis:

“Art. $8^{\circ}$.

$\S 2^{\circ} \mathrm{O}$ candidato não bacharel em direito, que pretender participar de concurso, deverá comprovar ter, até a data da primeira publicação do edital dez (10) anos de exercício em serviço notarial ou de registro, como titular, substituto ou escrevente juramentado, legalmente nomeado, apresentando, como documento comprobatório, certidão ou da Secretaria de Estado da Justiça e de Direitos Humanos, ou da Secretaria da Corregedoria-Geral de Justiça do respectivo Estado."

15. Destarte, a ofensa direta à Constituição é praticada não pela Resolução que reproduz o comando contido na referida lei estadual, mas por essa lei, que restou inatacada nestes autos. Descabe, pois, o controle concentrado. Esse colendo Supremo Tribunal Federal, como salientado inicialmente, fixou entendimento de que "não cabe ação direta de inconstitucionalidade contra Decreto que regulamenta Lei, ou porque, havendo divergência entre aquele e esta, a questão se situa primariamente no terreno da legalidade, ou porque, sendo a norma daquele mera reprodução da desta, a inconstitucionalidade a ser atacada é da norma legal e só por via de conseqüência se reflete na norma do Decreto que a repro$d u z^{\prime}$ (Adi n 2121/SC, Rel. Ministro MOREIRA ALVES, j. em 9/11/00, DJ de 15/12/00, p. 00060).

(...)" (fls. 167/171).

Carreto o parecer.

Os atos normativos impugnados são secundários, porque atos de regulamentação de norma primária, especialmente da Lei Estadual 12.919/98. A questão, portanto, comporta-se no campo do contencioso infraconstitucional. É que, se o regulamento vai além do conteúdo da lei, pratica ilegalidade e não inconstitucio- 
nalidade. No julgamento da ADI 1.253/DF, por mim relatada, decidiu o Supremo Tribunal Federal:

"EMENTA: CONSTITUCIONAL. ADMINISTRATIVO. DECRETO REGULAMENTAR. CONTROLE CONCENTRADO DE CONSTITUCIONALIDADE. Decreto $\mathrm{n}^{\circ}$ 982, de 12.IX.93.

I. - Decreto regulamentar não está sujeito ao controle de constitucionalidade, dado que se o decreto vai além do conteúdo da lei, pratica ilegalidade e não inconstitucionalidade. Somente na hipótese de não existir lei que preceda o ato regulamentar, é que poderia este ser acoimado de inconstitucional, assim sujeito ao controle de constitucionalidade.

II. - No caso, o Decreto 982, de 1993, destina-se, simplesmente, a regulamentar os atos dos agentes fiscais diante da ocorrência dos delitos inscritos no seu art. $1^{\circ}$, incisos I a XXII.

III. - ADIn não conhecida." ("D. J." de 25.8.95).

No meu voto, invoquei o decidido na $A D I$ 589/DF, também por mim relatada, cujo acórdão porta a seguinte ementa:

"EMENTA: CONSTITUCIONAL. ADMINISTRATIVO. DECRETO REGULAMENTAR. CONTROLE DE CONSTITUCIONALIDADE CONCENTRADO.

I. - Se o ato regulamentar vai além do conteúdo da lei, pratica ilegalidade. Neste caso, não há falar em inconstitucionalidade. Somente na hipótese de não existir lei que preceda o ato regulamentar, é que poderia este ser acoimado de inconstitucional, assim sujeito ao controle de constitucionalidade.

II. - Ato normativo de natureza regulamentar que ultrapassa o conteúdo da lei não está sujeito à jurisdição constitucional concentrada. Precedentes do STF: ADINs. $n^{\circ} \mathrm{s}$ 311/DF e 536/DF.

III. - Ação Direta de Inconstitucionalidade não conhecida." ("D.J." de 18.10.91).

Na ADI 1.383/RS, Relator Ministro Moreira Alves, o Supremo Tribunal Federal reiterou o entendimento $\mathrm{em}$ acórdão assim ementads:

"EMENTA: Ação direta de inconstitucionalidade. Dispositivos dos Provimentos n"s 8/95-CGJ, 34/95-CGJ e 39/95-CGJ da Corre-
gedoria-Geral da Justiça do Tribunal de Justiça do Estado do Rio Grande do Sul. Pedido de liminar.

- Esta Corte já firmou o entendimento de que só é cabível ação direta de inconstitucionalidade para verificar-se se há ofensa ao princípio constitucional da reserva legal ou de invasão de competência legislativa de um dos membros da Federação, quando o ato normativo impugnado é autônomo, ou seja, ato normativo que não vise a regulamentar lei ou que não se baseie nela, pois, caso contrário, a questão se situa primariamente no âmbito legal, não dando ensejo ao conhecimento da ação direta de inconstitucionalidade.

Ação de que não se conhece, ficando prejudicado o pedido de liminar." ("D. J." de 18.10.96).

No mesmo sentido a decisão prolatada pelo eminente Ministro Celso de Mello - ADI 2.207/AL, "D. J." de 04.9.2000 - na qual registrou, exemplarmente, S. Exa.:

"(...)

A jurisprudência do Supremo Tribunal Federal, ao refletir esse entendimento, firmou-se no sentido de repelir a possibilidade de controle jurisdicional de constitucionalidade, por via de ação, nas situações em que a impugnação in abstracto venha a incidir sobre atos, que, não obstante veiculadores de conteúdo normativo, ostentem caráter meramente ancilar ou secundário, precisamente porque editados em função das leis a que aderem e cujo texto pretendem regulamentar ou implementar:

"Às resoluções editadas pelo Poder Público, que veiculam regras de conteúdo meramente regulamentar, não se submetem à jurisdição constitucional de controle in abstracto, pois tais atos estatais têm por finalidade, em última análise, viabilizar, de modo direto $e$ imediato, a própria execução da lei.

Se a interpretação administrativa da lei divergir do sentido e do conteúdo da norma legal que o Decreto impugnado pretendeu regulamentar, quer porque se tenha projetado ulira legem, quer porque tenha permanecido citra legem, quer porque tenha investido contra legem, a questão posta em análise caracterizará típica crise de legalidade, e não de 
inconstitucionalidade, a inviabilizar a utilização do mecanismo processual de fiscalização normativa abstrata." (ADI 561-DF, Rel. Min. CELSO DE MELLO)

É por tal razão que esta Suprema Corte já advertiu que crises de legalidade - que irrompem no âmbito do sistema de direito positivo, caracterizadas pela inobservância, por parte da autoridade pública, do seu dever jurídico de subordinação normativa à lei — revelam-se, por sua natureza mesma, insuscetíveis de controle jurisdicional concentrando (RTJ 152/352, Rel. Min. CELSO DE MEL$\mathrm{LO}$ ), pois a finalidade a que se acha vinculado o processo de fiscalização normativa abstrata restringe-se, tão-somente, à aferição de situações configuradoras de inconstitucionalidade direta, imediata e frontal (RTJ 133/69. Rel. Min. CARLOS VELLOSO - RTJ 134/558, Rel. Min. CELSO DE MELLO - RTJ 139/67, Rel. Min. CELSO DE MELLO RTJ 137/580, Rel. Min. CARLOS VELLO$\mathrm{SO})$.

$$
\text { (...)" (“D. J." de 04.9.2000). }
$$

Do exposto, não conheço da presente ação, motivo por que nego seguimento ao pedido e determino o seu arquivamento.
(...)." (fls. 179-188)

A decisão é de ser mantida.

A uma, porque ajustada à jurisprudência da Casa, que não admite ação direta de inconstitucionalidade contra ato normativo secundário. No caso, os atos normativos impugnados são secundários, porque atos de regulamentação de norma primária, especialmente da Lei 12.919/98, do Estado de Minas Gerais. A duas, porque os precedentes indicados pelo agravante não se ajustam ao caso. A ADI 1.352/DF, Relator o Ministro Moreira Alves, teve como objeto decisão normativa do Tribunal de Justiça do Distrito Federal que determinou o pagamento, aos magistrados e servidores da Corte, da diferença acumulada do reajuste de vencimento de julho/87 pelo IPC, Índice de $26.06 \%$, retroativo ao período julho 1987 a novembro de 1988. sem lei que autorizasse dito reajuste. Na ADI 2.151/MG, Relator o Ministro Marco Aurélio, foi atacado, também, o $\S 2^{\circ}$ do art. $8^{\circ}$ da Lei $12.919 / 98$, do Estado de Minas Gerais, tendo a Corte deferido a suspensão cautelar da eficácia do citado $\S 2^{\circ}$ art. $8^{\circ}$ da Lei $12.919 / 98$.

Do exposto, nego provimento ao agravo. 